\title{
Application of OptiTrack motion capture systems in human movement analysis
}

\section{A systematic literature review}

\author{
Gergely Nagymáté, Rita M. Kiss \\ Department of Mechatronics, Optics and Mechanical Engineering Informatics \\ Budapest University of Technology and Economics \\ Budapest, Hungary \\ nagymate@mogi.bme.hu, rikiss@mail.bme.hu
}

\begin{abstract}
With the spreading of motion analysis decisions to invest into a new system demand scientific reference applications. The aim of the present systematic review is to reveal the biomechanical scientific applications of OptiTrack motion capture systems and to overview documented usage conditions and purposes. Six major scientific literature databases were used (PubMed, PubMed Central, ScienceDirect, IEEE Xplore, PLOS and Web Of Science). An OptiTrack camera system had to be used for human or biologically related motion capture. A total of 85 articles were included, 4 out of which dealt with the validation of OptiTrack systems and 81 utilized the system for biomechanical analyses. The data analysed and extracted from the system validation studies included: description of the validated and the reference system, measured features and observed errors. The data extracted from the utilizing studies also included: OptiTrack application, camera type and frequency, marker size, camera number, data processing software and the motion studied. The review offers a broad collection of biomechanical applications of OptiTrack motion capture systems as scientific references for certain motion studies. The review also summarizes findings on the accuracy of the systems. It concludes that the method descriptions of system usage are often underspecified
\end{abstract}

Keywords - OptiTrack; motion capture; biomechanics

\section{INTRODUCTION}

The application of optical motion capture systems has become increasingly widespread in the fields of entertainment [1], biomechanics [2] and sports sciences [3]. The operation of these systems is based on stereophotogrammetry where the three-dimensional coordinates of points on an object subject to measurements are produced in two or more photographic images taken from different positions. These systems consist of cameras, markers and processing software.

The spreading of motion analysis means that in addition to market-leading expensive high-end systems, such as Vicon (Oxford metrics, UK), cheaper camera systems appeared that were not specifically meant for scientific purposes, but sneaked in scientific motion labs. One such brand is OptiTrack (NaturalPoint, Corvallis, OR, USA), which was applied to the

This work was supported by the Hungarian Scientific Research Fund OTKA [grant number K115894] and BME-Biotechnology FIKP grant of EMMI [BME FIKP-BIO]. field of biomechanics from animation motion capture. Its main applications currently include virtual reality (VR), robotics, movement sciences and animations [4]. It has taken time for OptiTrack to become a scientifically accepted and used system as motion labs already rely on their own well-established highend motion capture systems. The spreading of cheaper systems also requires validation studies that compare the accuracy of new systems with scientific gold standard systems, representing an approach which researchers can relate to. Other possible important technical aspects of adequacy in a specific application are capture volume, minimum detectable marker size, frequency and resolution of the motion capture system.

Sometimes in biomechanical studies, selection of the motion analysis system is questioned when a system different from the gold standard Vicon systems is used. The scientific acceptance and usage of motion capture systems are measured by the number of studies in which they are utilized. The first aim of the present review is to investigate and organize the documented usage of OptiTrack systems through scientific database searches to serve as a collection of scientific biomechanical application references of the brand. The second aim is to summarize the results of system validation studies. The present study focuses on biomechanical applications in which qualitative measurements are performed mostly on human motion. The camera system parameters and data processing methodology are collected from the selected papers to detail the common application methods.

\section{METHODS}

\section{A. Search strategy}

1) Identification of materials

The goal of the search was to find studies in which the OptiTrack motion capture system was used for human motion analysis. We defined the search strategy using the simple keywords: 'optitrack' or 'opti-track'. These general keywords ensured that the search covered every application of the system. 
We ran the search query in six databases, PubMed, PubMed Central, ScienceDirect, IEEE Xplore, PLOS and Web Of Science, in September 2017. There were no publication date restrictions, and each publication was considered up to and including the date of the search. General guidelines for systematic reviews defined by the PRISMA statements [5] were considered during this research.

\section{2) Screening of materials}

Online database search results were screened by title, their abstract and their methods sections. In cases where OptiTrack usage was not clear from the abstract, the paper was searched for 'OptiTrack' or 'Opti-Track' to find occurrences and to reveal the camera system used in the study.

\section{3) Eligibility check of materials}

Papers were included for data extraction if they reported actual quantitative measurements of human movement. Exclusion criteria were applied to papers where robot motion tracking was analysed or where the purpose of human motion tracking was to enable a VR application or some other application without the need for precise motion capture. The inclusion criteria (TABLE I. ) applied were that an OptiTrack system had to be used in the paper for human or biologically related motion capture. Journal papers and conference proceedings were both included, with the only exception of abstract publications whose conditions were evaluated manually at this phase. The language of the papers included was specified as English, and papers that reported measurements with OptiTrack systems were downloaded for further processing following a file-naming convention involving the paper title. This strategy eliminated duplicated studies at the downloading stage to prevent duplicates from being downloaded multiple times. For paper data management, we used Mendeley Desktop v1.16.3 (Mendeley Ltd.). The full text of the downloaded papers was screened for study purposes and motion capture-related methodology and was classified into the following groups:

- research on system accuracy,

- biomechanical measurements,

- robotics-related motion tracking,

- VR application and

- other.

TABLE I. INCLUSION AND EXCLUSION CRITERIA

\begin{tabular}{|c|c|c|}
\hline & Inclusion criteria & Exclusion criteria \\
\hline Study type & $\begin{array}{l}\text { Journal papers } \\
\text { Books } \\
\text { Conference } \\
\text { proceedings }\end{array}$ & $\begin{array}{l}\text { Abstracts } \\
\text { Posters }\end{array}$ \\
\hline Language & English & Other languages \\
\hline $\begin{array}{ll}\text { OptiTrack } & \text { camera } \\
\text { system usage } & \end{array}$ & $\begin{array}{l}\text { Human or biologically } \\
\text { related motion capture } \\
\text { performed }\end{array}$ & $\begin{array}{l}\text { No measurement } \\
\text { performed }\end{array}$ \\
\hline
\end{tabular}

\section{B. Data extraction}

DOI: $10.17667 /$ riim.2018.1/13

Data extraction was performed on papers which were related to biomechanical measurements and those which involved studies into the accuracy of the systems. Being the main interest, research works on system accuracy and studies applying biomechanical measurements were further processed for data extraction. From system accuracy studies, we obtained the following key information:

- type and camera number of the validated OptiTrack system,

- type and camera number of the reference system,

- marker size,

- sampling frequency,

- description of reference measures and

- observed errors.

Possible bias of the results in system accuracy studies was assessed by their conflict of interest statements.

In the biomechanical measurement group, the following key points were collected into a table to explore the scientific usage of OptiTrack systems for biomechanical analyses:

- OptiTrack camera system application in the study (study concept),

- the camera system type used and the sampling frequency,

- camera number,

- applied post-processing software and

- motion studied.

Out of the biomechanical analyses carried out using motion capture systems, gait analysis was the most widely performed analysis. Therefore, the details of this application category were further studied and the following key points were extracted from papers pertaining to this category:

- subjects studied,

- walking speed,

- marker set,

- gait parameters calculated and

- comparisons performed on the data.

The distribution of the obtained data was statistically analyzed. The incidence rate of the different possibilities of the extracted data items was calculated. 


\section{RESULTS}

\section{A. Literature search results}

Fig. 1 demonstrates the complete PRISMA workflow, paper selection and grouping with paper numbers at each stage. The database searches clearly indicate that the number of yearly publications mentioning OptiTrack camera systems has progressively increased since 2011 . For the period prior to 2011, there were only a few publications in the searched databases, among which Oakeshott [6] was the first reported study that incorporated OptiTrack in 2003 to validate another approach for stride monitoring. The annual breakdown of the number of publications is as shown in Fig. 2.

The overall number of papers in the six databases searched was 412, which also includes duplicates. After the removal of duplicates, the number of papers was reduced to 248. Not every paper involved the use of an OptiTrack system or any other motion capture system, as some papers mentioned the camera system only in a different context. Out of this total, 107 papers were not relevant to the study as they failed to include biologically related experiments; instead, they discussed other related issues, e.g. pure robotic applications or robotic applications, where the camera system was only used for approximating the positions of a person [7]. For eligibility assessment, 141 studies were selected, and these involved biologically related experiments.

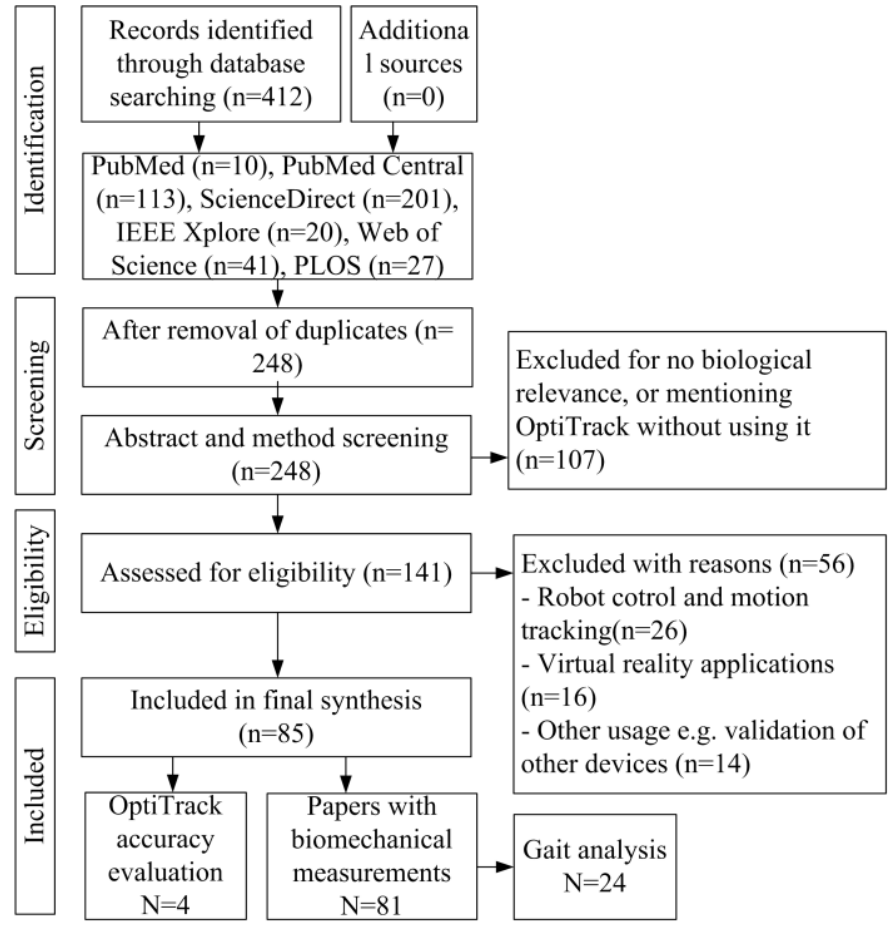

Fig. 1. PRISMA flow diagram of systematic review process.

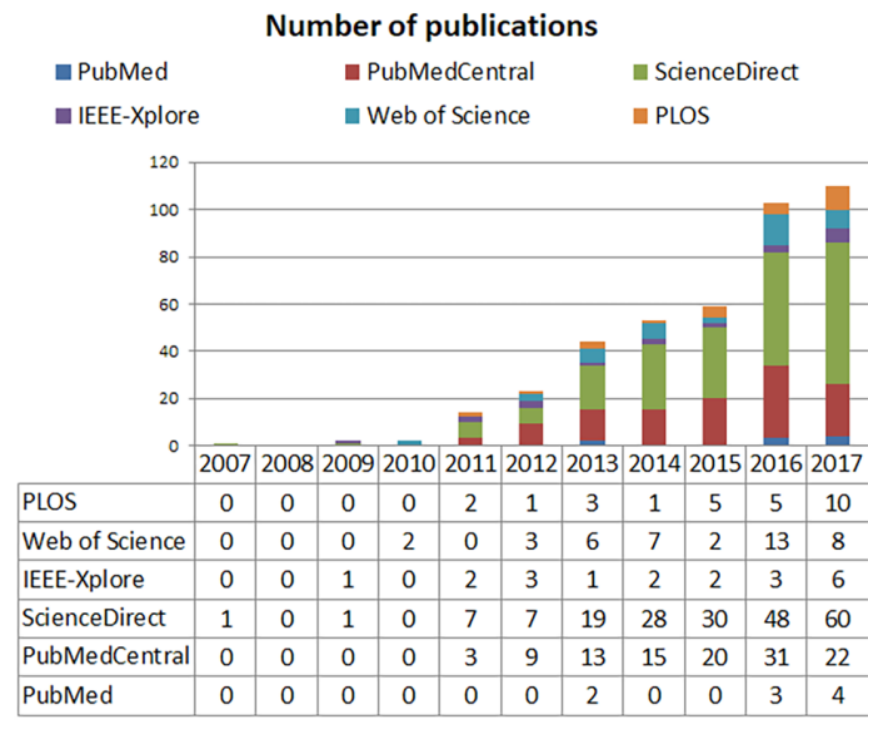

Fig. 2. Annual breakdown of the number of publications including Optitrack in the databases searched (as in September 2017).

We screened the selected papers, enabling them to be grouped into distinguishable application purposes, among which quantitative biomechanical human motion analyses or other quantitative biological motion analyses were our primary interest groups. The second interest group included studies that investigated the accuracy of OptiTrack systems. Further groups that were not processed were VR applications and robotics-related motion tracking. Some of the studies did not fit any of these categories, e.g. using the system for calibrating and validating another device [8]-[10], augmented reality games [11] or human activity recognition [12].

\section{B. OptiTrack system accuracy evaluation}

The database search revealed four papers [13]-[16] that aimed to validate the accuracy of OptiTrack systems. The main approach of three research studies [13]-[15] was to measure the known distance of rigidly fixed markers using the OptiTrack camera system and to evaluate the acquired deviations from the theoretical distance. Aurand et al. measured small relative marker displacement in different regions of a large capture volume [16]. TABLE II. summarizes the key information obtained by the comparisons described in these studies.

Thewlis et al. [13] compared the precision of a 12-camera Flex:V100R2 OptiTrack system and a 12-camera Vicon MXF20 camera system at $100 \mathrm{~Hz}$ with respect to static and dynamic linear accuracy (marker distance method) and gait kinematics. To do this, they simultaneously measured the marker coordinates placed on anatomical landmarks and calculated joint angles. They found that no absolute percentage errors were as large as $1 \%$ from the known distance, although they concluded that for gait kinematics, the OptiTrack system had a comparable accuracy to Vicon; however, in the knee and hip angles, they found differences larger than $3^{\circ}$ between the two systems [13]. 
Recent Innovations in Mechatronics (RIiM) Vol. 5. (2018). No. 1.

Carse et al. [14] compared a 8-camera Optitrack Flex:V100R2 system $(100 \mathrm{~Hz})$ with a 8 camera Vicon 612 $(120 \mathrm{~Hz})$ and a 12 -camera Vicon MX systems $(100 \mathrm{~Hz})$ using the marker distance method. The measured mean vector magnitudes of four markers on a rigid cluster characterized the systems by coefficients of variation, the largest disagreement between systems and the trajectory gaps. In their study, the Optitrack system obtained results which were similar to those of the Vicon 612 system; however, Vicon MX proved to be superior. The largest disagreements of mean vector magnitudes resulted at $2.2 \%$ for Optitrack vs. ViconMX, and $2.1 \%$ for Vicon 612 vs. Vicon MX. The coefficients of variation were as follows: Vicon MX $0.3 \%$, Vicon $6122.5 \%$, Optitrack 2.3\% [14].

Hansen et al. [15] tested a 10-camera OptiTrack 250e camera system $(250 \mathrm{~Hz})$ using the marker distance method under static and dynamic conditions with stationary marker clusters and by the motorized rotation of a marker cluster. The measurement accuracy was characterized by nine marker distances of static and rotating rigid bodies. The reference system was an 8-camera Vicon M2 camera system $(250 \mathrm{~Hz})$. They concluded that the system is sufficiently reliable for biomechanical analyses and other related fields, as the raw difference between the measurements for each system was only marginal (avg: 0.58 (SD: 0.25 ) $\mathrm{mm}$ for the nine distances ranging from 64 to $500 \mathrm{~mm}$ ) [15].

Aurand et al. [16] have studied the accuracy of a 42 camera OptiTrack Prime 41 system $(180 \mathrm{~Hz})$ measuring the small relative displacement of a single marker. The measurement was performed in different locations of a large measurement area. 3D error was measured compared to a ThorLabs LTS300 linear motion stage, which moved the marker with $5 \mu \mathrm{m}$ off-axis error in a maximum $100 \mathrm{~mm}$ range. They concluded that the worst error of these relative motions is less than $200 \mu \mathrm{m}$ in $97 \%$ of the $10.4 \mathrm{~mm} \mathrm{x} 6.5 \mathrm{~mm}$ measurement area, and reaches $1 \mathrm{~mm}$ error only at the edges of the measurement area.

Hansen [15], Carse [14] and Thewlis [13] declared no conflict of interest that could positively influence the outcome measures of their study. On the other hand in [16], the manufacturer of the OptiTrack systems provided the reference equipment and technical guidance to the measurements, which might result in a positive bias of the outcome measures.

TABLE II. SUMMARY OF OPTITRACK ACCURACY EVALUATION STUDIES.

\begin{tabular}{|c|c|c|c|c|}
\hline Study & $\begin{array}{c}\begin{array}{c}\text { Validated } \\
\text { system }\end{array} \\
\end{array}$ & $\begin{array}{c}\text { Reference } \\
\text { system }\end{array}$ & $\begin{array}{c}\text { Measured } \\
\text { feature }\end{array}$ & Observed errors \\
\hline [13] & $\begin{array}{l}\text { 12-camera } \\
\text { OptiTrack } \\
\text { Flex:V100R2 } \\
\text { Sampling: } \\
100 \mathrm{~Hz}\end{array}$ & $\begin{array}{l}\text { 12-camera } \\
\text { Vicon } \\
\text { MX-F20 } \\
\text { Sampling: } \\
100 \mathrm{~Hz}\end{array}$ & $\begin{array}{l}\text { Detected } \\
\text { marker } \\
\text { distances, } \\
\text { angular gait } \\
\text { parameters. } \\
\text { Marker } \\
\text { diameter: n/a }\end{array}$ & $\begin{array}{l}\text { Below } 1 \% \\
\text { deviation from } \\
\text { known length; the } \\
\text { largest relative } \\
\text { differences in gait } \\
\text { angular parameters } \\
\text { were below } 4^{\circ} \text {. }\end{array}$ \\
\hline [14] & $\begin{array}{l}\text { 8-camera } \\
\text { OptiTrack } \\
\text { Flex:V100R2 } \\
\text { Sampling: } \\
100 \mathrm{~Hz}\end{array}$ & $\begin{array}{l}\text { 12-camera } \\
\text { Vicon } \\
\text { MX } \\
\text { Sampling: } \\
100 \mathrm{~Hz}, 8-\end{array}$ & $\begin{array}{l}\text { Mean vector } \\
\text { magnitudes } \\
\text { of four } \\
\text { markers on a } \\
\text { rigid cluster; }\end{array}$ & 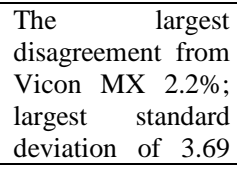 \\
\hline
\end{tabular}

DOI: $10.17667 /$ riim.2018.1/13

\begin{tabular}{|c|c|c|c|c|}
\hline & & $\begin{array}{l}\text { camera } \\
\text { Vicon } 612 \\
\text { Sampling: } \\
120 \mathrm{~Hz}\end{array}$ & $\begin{array}{l}\text { mean } \\
\text { coefficient of } \\
\text { variation. } \\
\text { Marker } \\
\text { diameter: } \\
16.5 \mathrm{~mm}\end{array}$ & $\begin{array}{lr}\mathrm{mm} \text { in detected } \\
\text { marker distance } \\
\text { and } & \text { mean } \\
\text { coefficient } & \text { of } \\
\text { variation of } 2.28 \\
\text { for OptiTrack. }\end{array}$ \\
\hline [15] & $\begin{array}{l}\text { 10-camera } \\
\text { OptiTrack } \\
\text { 250e } \\
\text { Sampling: } \\
250 \mathrm{~Hz}\end{array}$ & $\begin{array}{l}\text { 8-camera } \\
\text { Vicon M2 } \\
\text { Sampling: } \\
250 \mathrm{~Hz}\end{array}$ & $\begin{array}{l}\text { Marker } \\
\text { distances of } \\
\text { static and } \\
\text { rotating rigid } \\
\text { bodies. } \\
\text { Marker } \\
\text { diameters: } \\
\text { seven of } 14 \\
\text { mm and } \\
\text { three of } 9 \\
\text { mm }\end{array}$ & $\begin{array}{l}\text { Raw differences } \\
\text { between the } \\
\text { measurements for } \\
\text { each system are } \\
0.58(0.25) \mathrm{mm} \text {. }\end{array}$ \\
\hline [16] & $\begin{array}{l}42 \text { OptiTrack } \\
\text { Prime } 41 \\
\text { cameras } \\
\text { Sampling: } \\
180 \mathrm{~Hz}\end{array}$ & $\begin{array}{l}\text { ThorLabs } \\
\text { LTS300 } \\
\text { linear } \\
\text { motion } \\
\text { stage (on- } \\
\text { axis error } \\
\text { of } 5 \mu \mathrm{m} \text { ) }\end{array}$ & $\begin{array}{l}\text { Relative one } \\
\text { axial } \\
\text { displacement } \\
\text { of a single } \\
\text { marker. } \\
\text { Marker } \\
\text { diameter: } \\
15.9 \mathrm{~mm}\end{array}$ & $\begin{array}{l}\text { Less than } 200 \mu \mathrm{m} \\
\text { in } 97 \% \text { of the } \\
\text { capture volume }\end{array}$ \\
\hline
\end{tabular}

\section{Biomechanical applications}

The results of the application analysis for the key points described in the papers discussing biomechanical motion analysis are summarized in Table S1.The application fields are fairly diverse, even within biomechanical analyses. The most popular biomechanical application of OptiTrack systems is gait analysis. In the present context, papers involving the use of the term 'gait analysis' and those studies for which the authors measured lower limb kinematics during walking or running are considered for gait analysis applications. Out of the extracted papers, $29.6 \%$ (24 papers) of them belong to this category [17]-[40]. Papers in another large group (13.5\%, eleven papers) also involved measuring lower limb kinematics in activities other than walking, e.g. squat, stance or step-down tests [6], [41]-[50]. Another large application area is upper limb motion tracking (18.5\%, fifteen papers), where one or more upper limb joint angles or positions are measured [9], [10], [51]-[63]. This group includes finger movement tracking applications as well.

A smaller number of papers (approximately 7\%, five papers) reported the use of the OptiTrack camera system to track the motion of an external device, extending its measurement capabilities (e.g. an ultrasound imaging device [64], [65], inertial sensors [66], [67] or vibrations of a plate through which a person walks [68]). Seven studies $(8.6 \%)$ involved spinal motion analysis or detected postural changes or spinal movements on healthy participants [69]-[71] or cadavers using the system [72]-[75]. In two studies the focus was on measuring head position [76], [77]. One paper reported the use of the OptiTrack motion capture system to track mandibular movement [78].

Table S2 summarizes the results of further data extraction on gait analysis, which is the most widespread application of biomechanical studies. Table S2 presents details about the participants studied, the marker sets applied, the parameters 
calculated and the bases of comparisons in the gait studies using OptiTrack camera systems.

\section{Camera system type and camera number}

Camera types and numbers including sampling frequencies are listed in Table S1 (Column: Camera type and frequency). The majority of the studies failed to specify the camera type used $(55.5 \%, 45$ papers). In ten papers, FlexV100 cameras were used [18], [21], [27]-[30], [39], [55], [78], while twelve papers reported the use of Flex:V100R2 (manufacturer's rebranded name: Flex 3) cameras [9], [10], [41], [43], [46], [47], [64], [68], [70], [79]-[81]. A Flex 13 camera system was used in five studies [10], [36], [37], [44], [66], S250e cameras in two [26], [82] while V120 [83] were each used in a single study. The latest series of camera types were used in five papers: Prime13 in [58], [62], [84] and Prime41 in [56], [77]

Many papers (34 papers, 1.9\%) also failed to specify the sampling frequency. Out of the papers that failed to specify the camera type and sampling frequency, there was an overlap in $28.4 \%$ of the entire set (23 papers). Nineteen papers reported a $100-\mathrm{Hz}$ sampling frequency with respect to their camera system [17], [19], [27], [38], [39], [41], [43], [46], [47], [51], [52], [55], [57], [63], [64], [70], [75], [76], [78][80], [85]-[87], one reported $30 \mathrm{~Hz}$ [54], and fifteen studies sampled the motion at $120 \mathrm{~Hz}$ [26], [34], [36], [44], [45], [48]-[50], [56], [60], [62], [65], [71], [82], [84]. $150 \mathrm{~Hz}$ [88], 180 [77] and $240 \mathrm{~Hz}$ [33] sampling frequencies were applied by single papers. Nine papers [19], [34], [46], [52], [64], [84][87] specified a low-pass filter for the measured coordinates of tracking markers with cut-off frequencies ranging from 1 up to $10 \mathrm{~Hz}$.

The number of cameras utilized for the different setups are as displayed in Fig. 3. In approximately $25.9 \%$ of the studies, the authors failed to specify the number of cameras used in the motion capture system, while in most studies 6,10 or 12 cameras were used. The largest number of cameras used in the studies study was 24 [72], [79]-[81], [87].

A part of the camera systems are the markers used which also influence the accuracy of a measurement. Only nine papers specified the used marker size other than the system validation studies. Common marker sizes are $20 \mathrm{~mm} \mathrm{[18],}$ [27], [28] and $11 \mathrm{~mm}$ [46], [48], [64], [69] while $15 \mathrm{~mm}$ [62], $14 \mathrm{~mm}$ [47] $10 \mathrm{~mm}$ [21], $9.5 \mathrm{~mm}$ [65] and $8 \mathrm{~mm}$ [56] markers are also used.

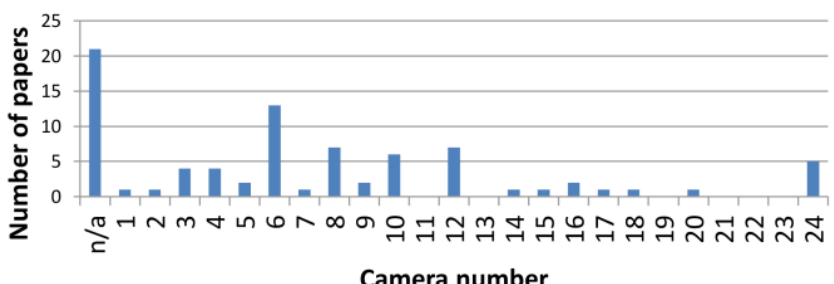

Camera number

Fig. 3. Number of cameras used.

\section{E. Processing software}

In processing the measured data and calculating the parameters studied, many papers specified the processing software (Table S1 Column: Data processing software). The most common motion-capture data processing software was Matlab, which was included in twenty-nine papers with individual scripts [9], [20], [25], [26], [28], [33], [36], [39], [41]-[44], [48]-[50], [56]-[58], [64]-[67], [70], [82]-[84], [89]-[91]. Nine papers mentioned the use of Visual3D [18], [19], [21], [27]-[30], [85], [86], which is one of the manufacturer's recommendations for biomechanical analysis with OptiTrack products [4]. One author [51] used a custom LabVIEW (National Instruments Inc., Austin, Texas) software.

\section{DISCUSSION}

The aim of the study is to investigate and organize the documented usage of OptiTrack systems through scientific database searches to serve as a collection of scientific biomechanical application references of the brand and to summarize the results of system validation studies. Our results show that an increasing number of publications discuss the use of OptiTrack systems each year, demonstrating their rising popularity in scientific applications (Fig. 2). However, the use of Vicon as the gold standard leads the way with 878 publications just in 2017 (until September), which was observed on 14/09/2017 in the six databases searched (the overall number of publications with Vicon in these databases is 10,439 ).

This increasing usage may be owing to the increasing number of system accuracy studies (TABLE II. ) proving the comparable accuracy of OptiTrack systems with high-end Vicon camera systems [13]-[16]. Two of these studies [13], [14] validated the Flex:V100R2 cameras, which are now rebranded to the still available small volume Flex 3 cameras [4]. The larger resolution S250e camera used in the third paper [15] is no longer available. A later higher resolution OptiTrack camera, the Prime series Ethernet cameras have also been scientifically validated, and they offer similar or higher accuracy [16]. Based on the validation studies, due to the joint effect of different system parameters and validation methods, marker size does not show a clear influence on accuracy; however, large camera resolution positively influences accuracy.

Some of the newer cameras (Flex 13, Prime series cameras) and many of the validated Flex:V100R2 and even older retired Flex:V100 cameras are being used for biomechanical measurements (Table S1). Typically tracked motions have already been discussed, but Table S1 also details the application purposes of these motion studies. The data collected clearly indicate the broadness of the application scope of OptiTrack camera systems. Human movement analyses which utilize the OptiTrack system cover diverse lower limb, upper limb, spinal motion and special (mandibular) motions, among which the most widespread biomechanical application is gait analysis (S1 Table). 
According to Table S2, the reported gait analysis studies cover different test subjects (pre- and post-surgery knee osteoarthritis patients, healthy subjects, athletes and diabetic neuropathy patients). The applied walking speed was mostly self-paced, and some studies involved the application of constant-speed treadmill walking or running trials. The marker sets described mostly included custom marker configurations. Most of the parameters considered in these studies were related to lower limb joint kinematics.

Regarding the papers studied, a common deficiency was that the majority of them failed to specify the camera type and sampling frequency used (Table S1). The resolution of the available OptiTrack cameras in September 2017 ranges from 0.3 to 4.1 megapixels, and the frame rate ranges from 100 to $360 \mathrm{~Hz}$ [4]. In contrast, Vicon camera resolution ranges from 1.3 to 16 megapixels and the maximum frame rate ranges from $120 \mathrm{~Hz}$ to $2000 \mathrm{~Hz}$ [92]. Also, only a few papers specified the size of the markers used; and the specified ones range from 9.5 to $20 \mathrm{~mm}$. These parameters, particularly the camera resolution, can significantly influence the acquired coordinate accuracy and thus the reliability of the measured data; therefore, it is essential to include them in the documentation of research articles. It is also important to document the number of cameras as it may also influence accuracy, as reported by Eichelberger [93]. A description of the number of cameras is also important from the perspective of the motion studied, as certain camera configurations and a minimal number of cameras may be required for specific tasks; e.g. gait analysis with only two cameras (e.g. a V120 dual-camera assembly) would provide questionable tracking continuity with respect to marker placement. Out of the reported camera counts, 6, 8- and 12-camera setups were the most common ones (Fig. 3). This may be owing to the fact that the Flex series of cameras are connected to a computer via a special six-slot USB hub. In cases such as these, the motion labs may be equipped with as many cameras as there are slots that they possess on one or two hubs.

Only seven papers [18], [19], [21], [27]-[30] used the Visual3D software to process the marker coordinates into the desired motion (mostly joint angular) parameters (S1 Table). Most studies (14) performed the calculations using custom Matlab scripts (S1 Table). However, the software used may have the least effect on the outcome measures as the calculations (e.g. calculation of joint angles from the specified marker coordinates) of the applied models are more important, which is usually not described in the papers.

\section{A. Limitations of this study}

This systematic review was not registered and thus no review protocols are available online or otherwise. Other limitations can arise from the fact that only six major scientific databases were used in the search for materials, and no additional sources. The OptiTrack system was a measurement tool in the individual biomechanical studies of diverse research subjects, thus the assessment of the risk of bias on their results could not be performed related to the goal of this systematic review.

\section{CONCLUSION}

In the present study, we aimed to present an overview of the growing number of biomechanical applications of OptiTrack camera systems, which are slowly emerging as competitors of the gold standard Vicon in scientific applications. The second aim was to present an overview of the results of validation studies which tested the precision of OptiTrack camera systems compared to that of Vicon systems. The paper presents many applications in which OptiTrack camera systems were used for quantitative biomechanical, mostly human related, measurements. Several of the common OptiTrack motion capture setups and data processing software tools popular in this field were presented. According to the study, the majority of the papers that were included underdocument their system setups (camera type, frame rate, marker size and number of cameras). These shortcomings prevent the sharing of valuable information on system accuracy and measurement repeatability, and these should be subsequently included in scientific papers to improve the repeatability and reproducibility of the studies.

Supplementary materials are available online in a public data repository: https://github.com/motionlab-mogi-

bme/Application-of-OptiTrack-motion-capture-systems-in$\underline{\text { human-movement-analysis }}$

\section{REFERENCES}

[1] C. Bregler, "Motion Capture Technology for Entertainment [In the Spotlight]," IEEE Signal Process. Mag., vol. 24, no. 6, pp. 160-158, Nov. 2007.

[2] D. . Sutherland, "The evolution of clinical gait analysis," Gait Posture, vol. 16, no. 2, pp. 159-179, Oct. 2002.

[3] R. R. Bini, F. Diefenthaeler, and C. B. Mota, "Fatigue effects on the coordinative pattern during cycling: Kinetics and kinematics evaluation," J. Electromyogr. Kinesiol., vol. 20, no. 1, pp. 102-107, 2010.

[4] NaturalPoint, "Motion Capture Systems - OptiTrack Webpage." [Online]. Available: optitrack.com. [Accessed: 09-Jan-2017].

[5] A. Liberati et al., "Annals of Internal Medicine Academia and Clinic The PRISMA Statement for Reporting Systematic Reviews and MetaAnalyses of Studies That Evaluate Health Care Interventions :," Ann. Intern. Med., vol. 151, no. 4, pp. W65-W94, 2009.

[6] R. Oakeshott, J. B. Stiehl, R. A. Komistek, D. T. Anderson, and B. D Haas, "Kinematic Analysis of a Posterior Cruciate Retaining MobileBearing Total Knee Arthroplasty,” J. Arthroplasty, vol. 18, no. 8, pp. 1029-1037, 2003.

[7] W. Ye, Z. Li, C. Yang, J. Sun, C. Y. Su, and R. Lu, "Vision-Based Human Tracking Control of a Wheeled Inverted Pendulum Robot," IEEE Trans. Cybern., vol. 46, no. 11, pp. 2423-2434, 2015.

[8] F. Vasconcelos, D. Peebles, S. Ourselin, and D. Stoyanov, "Spatial calibration of a $2 \mathrm{D} / 3 \mathrm{D}$ ultrasound using a tracked needle," Int. J. Comput. Assist. Radiol. Surg., vol. 11, no. 6, pp. 1091-1099, 2016.

[9] D. Webster and O. Celik, "Experimental evaluation of Microsoft Kinect's accuracy and capture rate for stroke rehabilitation applications," in 2014 IEEE Haptics Symposium (HAPTICS), 2014, vol. 39, no. 4, pp. 455-460.

[10] E. Gezgin, P. H. Chang, and A. F. Akhan, "Synthesis of a Watt II sixbar linkage in the design of a hand rehabilitation robot," Mech. Mach. Theory, vol. 104, pp. 177-189, 2016.

[11] S. Zhang, K. H. Leo, B. Y. Tan, and R. Q. F. Tham, "A hybrid human motion tracking system for virtual rehabilitation," Proc. 2011 6th IEEE Conf. Ind. Electron. Appl. ICIEA 2011, pp. 1993-1998, 2011. 
[12] C. Zhu and W. Sheng, "Motion- and location-based online human daily activity recognition," Pervasive Mob. Comput., vol. 7, no. 2, pp. 256269, 2011.

[13] D. Thewlis, C. Bishop, N. Daniell, and G. Paul, "Next-generation lowcost motion capture systems can provide comparable spatial accuracy to high-end systems.," J. Appl. Biomech., vol. 29, no. 1, pp. 112-7, Feb. 2013.

[14] B. Carse, B. Meadows, R. Bowers, and P. Rowe, "Affordable clinica gait analysis: An assessment of the marker tracking accuracy of a new low-cost optical 3D motion analysis system," Physiother. (United Kingdom), vol. 99, no. 4, pp. 347-351, 2013.

[15] C. Hansen, D. Gibas, J.-L. Honeine, N. Rezzoug, P. Gorce, and B. Isableu, "An inexpensive solution for motion analysis," Proc. Inst. Mech. Eng. Part P J. Sport. Eng. Technol., vol. 228, no. 3, pp. 165170, Sep. 2014

[16] A. M. Aurand, J. S. Dufour, and W. S. Marras, "Accuracy map of an optical motion capture system with 42 or 21 cameras in a large measurement volume," J. Biomech., vol. 58, pp. 237-240, Jun. 2017.

[17] G.-Y. Chung, G.-S. Choi, K.-Y. Shin, and J.-S. Park, "Gait changes after using a temporomandibular joint exerciser in patients who underwent lower limb joint surgery," J. Phys. Ther. Sci., vol. 28, no. 5, pp. 1584-1587, 2016.

[18] C. D. Sartor, R. Watari, A. C. Pássaro, A. P. Picon, R. H. Hasue, and I. C. Sacco, "Effects of a combined strengthening, stretching and functional training program versus usual-care on gait biomechanics and foot function for diabetic neuropathy: a randomized controlled trial," BMC Musculoskelet. Disord., vol. 13, no. 1, p. 36, Dec. 2012.

[19] L. Hutchison, R. Scharfbillig, H. Uden, and C. Bishop, "The effect of footwear and foot orthoses on transverse plane knee motion during running - A pilot study," J. Sci. Med. Sport, vol. 18, no. 6, pp. 748-752, 2015 .

[20] B. E. Lawson, B. Ruhe, A. Shultz, and M. Goldfarb, "A Powered Prosthetic Intervention for Bilateral Transfemoral Amputees," IEEE Trans. Biomed. Eng., vol. 62, no. 4, pp. 1042-1050, Apr. 2015.

[21] A. B. Matias, U. T. Taddei, M. Duarte, and I. C. N. Sacco, "Protocol for evaluating the effects of a therapeutic foot exercise program on injury incidence, foot functionality and biomechanics in long-distance runners: a randomized controlled trial.," BMC Musculoskelet. Disord., vol. 17 , no. 1 , p. 160,2016

[22] N. Mijailovic, R. Vulovic, I. Milankovic, R. Radakovic, N. Filipovic, and A. Peulic, "Assessment of knee cartilage stress distribution and deformation using motion capture system and wearable sensors for force ratio detection," Comput. Math. Methods Med., vol. 2015, 2015.

[23] S. T. Moore, H. G. MacDougall, J. M. Gracies, H. S. Cohen, and W. G. Ondo, "Long-term monitoring of gait in Parkinson's disease," Gait Posture, vol. 26, no. 2, pp. 200-207, 2007.

[24] S. Murray and M. Goldfarb, "Towards the use of a lower limb exoskeleton for locomotion assistance in individuals with neuromuscular locomotor deficits," in 2012 Annual International Conference of the IEEE Engineering in Medicine and Biology Society, 2012, vol. 100, no. 2, pp. 1912-1915.

[25] M. Nishimura, N. Takahira, K. Fukushima, K. Uchiyama, M. Moriya, and T. Yamamoto, "Comparison of Gait Motion Including Postoperative Trunk Deflection Between Direct Lateral and Anterolateral Approaches in Supine Total Hip Arthroplasty," J. Arthroplasty, vol. 31, no. 7, pp. 1603-1608, 2016.

[26] A. H. Shultz, J. E. Mitchell, D. Truex, B. E. Lawson, E. Ledoux, and M. Goldfarb, "A walking controller for a powered ankle prosthesis," in 2014 36th Annual International Conference of the IEEE Engineering in Medicine and Biology Society, 2014, vol. 33, no. 4, pp. 6203-6206.

[27] E. Y. Suda, A. A. Gomes, M. K. Butugan, and I. C. N. Sacco, "Muscle fiber conduction velocity in different gait phases of early and late-stage diabetic neuropathy," J. Electromyogr. Kinesiol., vol. 30, pp. 263-271, 2016.

[28] F. Trombini-Souza et al., "Effectiveness of a long-term use of a minimalist footwear versus habitual shoe on pain, function and mechanical loads in knee osteoarthritis: a randomized controlled trial," BMC Musculoskelet. Disord., vol. 13, no. 1, p. 121, 2012.
[29] F. Trombini-Souza et al., "Long-term use of minimal footwear on pain, self-reported function, analgesic intake, and joint loading in elderly women with knee osteoarthritis: A randomized controlled trial," Clin. Biomech., vol. 30, no. 10, pp. 1194-1201, 2015.

[30] F. Trombini-Souza et al., "Inexpensive footwear decreases joint loading in elderly women with knee osteoarthritis," Gait Posture, vol. 34, no. 1, pp. 126-130, 2011.

[31] H. Cook, K. Tucker, W. van den Hoorn, D. Button, and M. Smith, "Proximal lower limb kinematics differ in people with chronic ankle instability compared to controls during treadmill walking," Man. Ther. vol. 25, no. 2016, p. e36, 2016.

[32] B. Hanssen, S. H. Schless, M. Goudriaan, L. Bar-On, and K. Desloovere, "Can muscle morphology and internal composition of lower limb muscles explain strength and gait deficits in children with spastic cerebral palsy?," Gait Posture, vol. 57, pp. 114-115, 2017.

[33] R. Hashish, M. E. Toney-Bolger, S. S. Sharpe, B. D. Lester, and A. Mulliken, "Texting during stair negotiation and implications for fall risk," Gait Posture, vol. 58, no. August, pp. 409-414, 2017.

[34] H. Hicheur, C. Boujon, C. Wong, Q. C. Pham, J. M. Annoni, and T. Bihl, "Planning of spatially-oriented locomotion following focal brain damage in humans: A pilot study," Behav. Brain Res., vol. 301, pp. 33 42, 2016.

[35] Z. Matjačić, M. Zadravec, and A. Olenšek, "An effective balancing response to lateral perturbations at pelvis level during slow walking requires control in all three planes of motion," J. Biomech., vol. 60, pp. 79-90, 2017.

[36] K. E. Peyer, C. A. Brassey, K. A. Rose, and W. I. Sellers, "Locomotion pattern and foot pressure adjustments during gentle turns in healthy subjects," J. Biomech., vol. 60, pp. 65-71, 2017.

[37] H. De Vroey et al., "Correlation between an inertial and camera based system for the assessment of temporal parameters of gait in the knee arthroplasty population," Gait Posture, vol. 57, no. xxxx, pp. 280-281, 2017.

[38] S. Ota, Y. Ogawa, H. Ota, T. Fujiwara, T. Sugiyama, and A. Ochi, "Beneficial effects of a gait used while wearing a kimono to decrease the knee adduction moment in healthy adults," PLoS One, vol. 12, no. 6, p. e0179260, Jun. 2017.

[39] K. Nishida, S. Hagio, B. Kibushi, T. Moritani, and M. Kouzaki, "Comparison of muscle synergies for running between different foot strike patterns," PLoS One, vol. 12, no. 2, pp. 1-19, 2017.

[40] L. C. Yi, C. D. Sartor, F. T. Souza, and I. C. N. Sacco, "Intralimb Coordination Patterns in Absent, Mild, and Severe Stages of Diabetic Neuropathy: Looking Beyond Kinematic Analysis of Gait Cycle," PLoS One, vol. 11, no. 1, p. e0147300, 2016.

[41] T. Bell-Jenje, B. Olivier, W. Wood, S. Rogers, A. Green, and W. McKinon, "The association between loss of ankle dorsiflexion range of movement, and hip adduction and internal rotation during a step down test," Man. Ther., vol. 21, pp. 256-261, 2016.

[42] C. Dafkin et al., "Kinematic and kinetic analysis of the inter- and intraapplicator assessment of the Babinski reflex," Neurophysiol. Clin., vol. 44, no. 5, pp. 471-477, 2014

[43] F. Gholami, R. Pàmies-Vilà, J. Kövecses, and J. M. Font-Llagunes, "Effects of foot modelling on the human ankle kinematics and dynamics," Mech. Mach. Theory, vol. 93, pp. 175-184, 2015.

[44] M. L. Roemhildt, M. G. Gardner-Morse, C. F. Morgan, B. D. Beynnon, and G. J. Badger, "Calcium phosphate particulates increase friction in the rat knee joint," Osteoarthr. Cartil., vol. 22, no. 5, pp. 706-709, 2014.

[45] H. Tanikawa, M. Tada, K. Harato, K. Okuma, and T. Nagura, "Influence of Total Knee Arthroplasty on Patellar Kinematics and Patellofemoral Pressure.," J. Arthroplasty, 2016.

[46] A. Yamamoto, S. Sasagawa, N. Oba, and K. Nakazawa, "Behavioral effect of knee joint motion on body's center of mass during human quiet standing," Gait Posture, vol. 41, no. 1, pp. 291-294, 2015.

[47] N. Yoshida et al., "Effect of Forefoot Strike on Lower Extremity Muscle Activity and Knee Joint Angle During Cutting in Female Team Handball Players," Sport. Med. - Open, vol. 2, no. 1, p. 32, 2016. 
[48] B. M. Kalkman et al., "Achilles tendon moment arm length is smaller in children with cerebral palsy than in typically developing children," $J$. Biomech., vol. 56, pp. 48-54, 2017.

[49] B. Kalkman et al., "Passive muscle and tendon properties during ankle joint rotation in children with cerebral palsy," Gait Posture, vol. 49, pp. 2-3, 2016.

[50] B. J. Raiteri, F. Hug, A. G. Cresswell, and G. A. Lichtwark, "Quantification of muscle co-contraction using supersonic shear wave imaging," J. Biomech., vol. 49, no. 3, pp. 493-495, 2016.

[51] D. Ao, R. Song, and K. Y. Tong, "Sensorimotor control of tracking movements at various speeds for stroke patients as well as age-matched and young healthy subjects," PLoS One, vol. 10, no. 6, pp. 1-15, 2015.

[52] F. Fraysse and D. Thewlis, "Comparison of anatomical, functional and regression methods for estimating the rotation axes of the forearm," $J$. Biomech., vol. 47, no. 14, pp. 3488-3493, 2014.

[53] H. Hirai et al., "On the Origin of Muscle Synergies: Invariant Balance in the Co-activation of Agonist and Antagonist Muscle Pairs," Front Bioeng Biotechnol, vol. 3, no. November, p. 192, 2015.

[54] K. L. Mardula, R. Balasubramanian, and C. H. Allan, "Implanted passive engineering mechanism improves hand function after tendon transfer surgery: a cadaver-based study," Hand, vol. 10, no. 1, pp. 116$122,2015$.

[55] A. Ohnishi, M. Takanokura, and A. Sugama, "Evaluation of Interhandle Distance During Pushing and Pulling of a Four-Caster Cart for Upper Limb Exertion," Saf. Health Work, vol. 7, no. 3, pp. 237 243, Sep. 2016.

[56] R. F. Zulkarnain, G. Y. Kim, A. Adikrishna, H. P. Hong, Y. J. Kim, and I. H. Jeon, "Digital data acquisition of shoulder range of motion and arm motion smoothness using Kinect v2," J. Shoulder Elb. Surg., vol. 26, no. 5, pp. 895-901, 2017.

[57] A. Akhtar, N. Aghasadeghi, L. Hargrove, and T. Bretl, "Estimation of distal arm joint angles from EMG and shoulder orientation for transhumeral prostheses," J. Electromyogr. Kinesiol., vol. 35, pp. 8694, 2017.

[58] I. Cerulo, F. Ficuciello, V. Lippiello, and B. Siciliano, "Teleoperation of the SCHUNK S5FH under-actuated anthropomorphic hand using human hand motion tracking," Rob. Auton. Syst., vol. 89, pp. 75-84, 2017.

[59] H. Kang and G. Shin, "Effects of touch target location on performance and physical demands of computer touchscreen use," Appl. Ergon., vol. 61, pp. 159-167, 2017.

[60] M. Khoramshahi, A. Shukla, S. Raffard, B. G. Bardy, and A. Billard, "Role of gaze cues in interpersonal motor coordination: Towards higher affiliation in human-robot interaction," PLoS One, vol. 11, no. 6, pp. 121, 2016.

[61] K. Seo, J. Kim, D. H. Oh, H. Ryu, and H. Choi, "Virtual daily living test to screen for mild cognitive impairment using kinematic movement analysis," PLoS One, vol. 12, no. 7, p. e0181883, Jul. 2017.

[62] K. Shinohara, N. Yamauchi, S. Kawahara, and H. Tanaka, "Takete and Maluma in action: A cross-modal relationship between gestures and sounds," PLoS One, vol. 11, no. 9, pp. 1-17, 2016.

[63] P. J. Maes and M. Leman, "The Influence of Body Movements on Children's Perception of Music with an Ambiguous Expressive Character," PLoS One, vol. 8, no. 1, 2013.

[64] R. D. Herbert, M. E. Héroux, J. Diong, L. E. Bilston, S. C. Gandevia, and G. A. Lichtwark, "Changes in the length and three-dimensional orientation of muscle fascicles and aponeuroses with passive length changes in human gastrocnemius muscles," J. Physiol., vol. 593, no. 2, pp. 441-455, Jan. 2015.

[65] B. J. Raiteri, A. G. Cresswell, and G. A. Lichtwark, "Threedimensional geometrical changes of the human tibialis anterior muscle and its central aponeurosis measured with three-dimensional ultrasound during isometric contractions," PeerJ, vol. 4, p. e2260, Jul. 2016.

[66] Y. Suh, "Inertial Sensor-Based Smoother for Gait Analysis," Sensors, vol. 14, no. 12, pp. 24338-24357, Dec. 2014.

[67] S. Gleadhill, J. B. Lee, and D. James, "The development and validation of using inertial sensors to monitor postural change in resistance exercise," J. Biomech., vol. 49, no. 7, pp. 1259-1263, 2016.
[68] Y. Visell, B. L. Giordano, G. Millet, and J. R. Cooperstock, "Vibration Influences Haptic Perception of Surface Compliance During Walking," PLoS One, vol. 6, no. 3, p. e17697, Mar. 2011.

[69] A. Yamamoto et al., "Method for measuring tri-axial lumbar motion angles using wearable sheet stretch sensors," PLoS One, vol. 12, no. 10, p. e0183651, Oct. 2017.

[70] A. Keizer, M. A. M. Smeets, H. C. Dijkerman, S. A. Uzunbajakau, A. van Elburg, and A. Postma, "Too Fat to Fit through the Door: First Evidence for Disturbed Body-Scaled Action in Anorexia Nervosa during Locomotion," PLoS One, vol. 8, no. 5, pp. 1-7, 2013.

[71] M. D'Amico, E. Kinel, and P. Roncoletta, Normative 3D optoelectronic stereophotogrammetric posture and spine morphology data in young healthy adult population, vol. 12, no. 6. 2017.

[72] P. Le and W. S. Marras, "Evaluating the low back biomechanics of three different office workstations: Seated, standing, and perching," Appl. Ergon., vol. 56, pp. 170-178, 2016.

[73] H. Xu, S. Jampala, D. Bloswick, J. Zhao, and A. Merryweather, "Evaluation of knee joint forces during kneeling work with different kneepads," Appl. Ergon., vol. 58, pp. 308-313, 2017.

[74] C.-C. Yu et al., "The Role of Posterior Longitudinal Ligament in Cervical Disc Replacement: An Ovine Cadaveric Biomechanical Analysis," Med. Sci. Monit., vol. 22, pp. 1843-1849, 2016.

[75] X. Zhu and G. Shin, "Kinematics and muscle activities of the lumbar spine during and after working in stooped postures," J. Electromyogr. Kinesiol., vol. 23, no. 4, pp. 801-806, 2013.

[76] M. Boulanger, G. Giraudet, and J. Faubert, "Interaction between the oculomotor and postural systems during a dual-task: Compensatory reductions in head sway following visually-induced postural perturbations promote the production of accurate double-step saccades in standing human adults," PLoS One, vol. 12, no. 3, pp. 1-20, 2017.

[77] E. Frid, R. Bresin, P. Alborno, and L. Elblaus, "Interactive sonification of spontaneous movement of children-cross-modal mapping and the perception of body movement qualities through sound," Front. Neurosci., vol. 10, no. NOV, 2016.

[78] D. A. Furtado, A. A. Pereira, A. D. O. Andrade, D. P. Bellomo, and M. R. da Silva, "A specialized motion capture system for real-time analysis of mandibular movements using infrared cameras.," Biomed. Eng. Online, vol. 12, p. 17, 2013.

[79] J. Hwang et al., "Validation of a personalized curved muscle model of the lumbar spine during complex dynamic exertions," J. Electromyogr. Kinesiol., vol. 33, pp. 1-9, 2017.

[80] J. Hwang et al., "A biologically-assisted curved muscle model of the lumbar spine: Model validation," Clin. Biomech., vol. 37, pp. 153-159, 2016.

[81] P. Le et al., "Development and testing of a moment-based coactivation index to assess complex dynamic tasks for the lumbar spine," Clin. Biomech., vol. 46, no. August 2016, pp. 23-32, 2017.

[82] T. Giraud, F. Focone, B. Isableu, J. C. Martin, and V. Demulier, "Impact of elicited mood on movement expressivity during a fitness task," Hum. Mov. Sci., vol. 49, pp. 9-26, 2016.

[83] E. Růžička, R. Krupička, K. Zárubová, J. Rusz, R. Jech, and Z. Szabó, "Tests of manual dexterity and speed in Parkinson's disease: Not all measure the same," Park. Relat. Disord., vol. 28, pp. 118-123, 2016.

[84] S. L. Alberico, Y. C. Kim, T. Lence, and N. S. Narayanan, "Axial levodopa-induced dyskinesias and neuronal activity in the dorsal striatum," Neuroscience, vol. 343, pp. 240-249, 2017.

[85] A. H. Huntley, J. L. Zettel, and L. A. Vallis, "Older adults exhibit altered motor coordination during an upper limb object transport task requiring a lateral change in support," Hum. Mov. Sci., vol. 52, pp. 133-142, Apr. 2017.

[86] A. H. Huntley, J. L. Zettel, and L. A. Vallis, "Effect of aging on dynamic postural stability and variability during a multi-directional lean and reach object transportation task," Arch. Gerontol. Geriatr., vol. 66, pp. 154-160, 2016.

[87] E. Weston, P. Le, and W. S. Marras, "A biomechanical and physiological study of office seat and tablet device interaction," Appl. Ergon., vol. 62, pp. 83-93, 2017. 
[88] C. Lee, S. Lee, and G. Shin, "Reliability of forward head posture evaluation while sitting, standing, walking and running," Hum. Mov. Sci., vol. 55, no. January, pp. 81-86, 2017.

[89] S. M. Beaudette, D. P. Zwambag, L. R. Bent, and S. H. M. Brown, "Spine postural change elicits localized skin structural deformation of the trunk dorsum in vivo," J. Mech. Behav. Biomed. Mater., vol. 67, no. August 2016, pp. 31-39, 2017.

[90] J. B. Shepherd, D. D. Rowlands, and D. A. James, "A Skill Acquisition Based Framework for Aiding Lower Limb Injury Rehabilitation using a Single Inertial Sensor with Concurrent Visual Feedback," Procedia Eng., vol. 147, pp. 632-636, 2016.
[91] A. M. Zaferiou, H. Flashner, R. R. Wilcox, and J. L. McNitt-Gray, "Lower extremity control during turns initiated with and without hip external rotation," J. Biomech., vol. 52, pp. 130-139, 2017.

[92] Vicon Motion Systems LTD, "Build My Motion Capture System VICON." [Online]. Available: https://www.vicon.com/visualization. [Accessed: 09-Jun-2017].

[93] P. Eichelberger et al., "Analysis of accuracy in optical motion capture A protocol for laboratory setup evaluation," J. Biomech., vol. 49, no. 10, pp. 2085-2088, Jul. 2016 